\title{
Fuchs endothelial corneal dystrophy
}

INSERM

\section{Source}

INSERM. (1999). Orphanet: an online rare disease and orphan drug data base. Fuchs endothelial corneal dystrophy. ORPHA:98974

Fuchs endothelial corneal dystrophy (FECD) is the most frequent form of posterior corneal dystrophy (see this term) and is characterized by excrescences on a thickened Descemet membrane (corneal guttae), generalized corneal edema, with gradually decreased visual acuity. 